\title{
REVIEWS
}

\section{Evidence Review-Social Determinants of Health for Veterans}

\author{
Wei Duan-Porter, MD, $P h D^{1,2}$, Brian C. Martinson, $P h D^{1,3,4}$, Nancy Greer, $P h D^{7}$, \\ Brent C. Taylor, $\mathrm{PhD}^{1,2,4}$, Kristen Ullman, $\mathrm{MPH}^{7}$, Lauren McKenzie, $\mathrm{MPH}^{7}$, Christina Rosebush, $\mathrm{MPH}^{7}$, \\ Roderick MacDonald, $\mathrm{MS}^{7}$, Samuel Falde, $\mathrm{BS}^{2}$, and Timothy J. Wilt, $M D, M P H^{1,2}$
}

\footnotetext{
${ }^{1}$ Center for Chronic Disease Outcomes Research, Minneapolis VA Health Care System HSR\&D, Minneapolis, MN, USA; ${ }^{2}$ University of Minnesota Medical School, Minneapolis, MN, USA; ${ }^{3}$ HealthPartners Institute, Bloomington, MN, USA; ${ }^{4}$ School of Public Health, University of Minnesota, Minneapolis, MN, USA
}

BACKGROUND: Veterans Health Administration (VHA) is committed to providing high-quality care and addressing health disparities for vulnerable Veterans. To meet these goals, VA policymakers need guidance on how to address social determinants in operations planning and day-today clinical care for Veterans.

METHOD: MEDLINE (OVID), CINAHL, PsycINFO, and Sociological Abstracts were searched from inception to January 2017. Additional articles were suggested by peer reviewers and/or found through search of work associated with US and VA cohorts. Eligible articles compared Veterans vs non-Veterans, and/or Veterans engaged with those not engaged in VA healthcare. Our evidence maps summarized study characteristics, social determinant(s) addressed, and whether health behaviors, health services utilization, and/or health outcomes were examined. Qualitative syntheses and quality assessment were performed for articles on rurality, trauma exposure, and sexual orientation.

RESULTS: We screened 7242 citations and found 131 eligible articles-99 compared Veterans vs non-Veterans, and 40 included engaged vs non-engaged Veterans. Most articles were cross-sectional and addressed socioeconomic factors (e.g., education and income). Fewer articles addressed rurality $(N=20)$, trauma exposure $(N=17)$, or sexual orientation $(N=2)$; none examined gender identity. We found no differences in rural residence between Veterans and non-Veterans, nor between engaged and nonengaged Veterans (moderate strength evidence). There was insufficient evidence for role of rurality in health behaviors, health services utilization, or health outcomes. Trauma exposures, including from events preceding military service, were more prevalent for Veterans vs nonVeterans and for engaged vs non-engaged Veterans (lowstrength evidence); exposures were associated with smoking (low-strength evidence).

Prior Presentations Results from this evidence review were presented as a poster at the national VA Health Services Research \& Development/ QUERI meeting in July 2017

Electronic supplementary material The online version of this article (https://doi.org/10.1007/s11606-018-4566-8) contains supplementary material, which is available to authorized users.

Received March 21, 2018

Revised June 7, 2018

Accepted June 30, 2018

Published online July 20, 2018
DISCUSSION: Little published literature exists on some emerging social determinants. We found no differences in rural residence between our groups of interest, but trauma exposure was higher in Veterans (vs non-Veterans) and engaged (vs non-engaged). We recommend consistent measures for social determinants, clear conceptual frameworks, and analytic strategies that account for the complex relationships between social determinants and health.

KEY WORDS: vulnerable populations; socioeconomic factors; population health.

J Gen Intern Med 33(10):1785-95

DOI: $10.1007 / \mathrm{s} 11606-018-4566-8$

(c) Society of General Internal Medicine (This is a U.S. government work and not under copyright protection in the U.S.; foreign copyright protection may apply) 2018

\section{INTRODUCTION}

Social determinants of health, especially those factors which define socioeconomic status (e.g., education and income), substantially influence health outcomes and healthcare utilization across the lifecourse, contributing to health disparities for disadvantaged groups. ${ }^{1-7}$ While acknowledging the importance of social determinants for population health, healthcare organizations and providers need guidance on how to assess and incorporate social determinants into policy, operations planning, and day-to-day clinical care. ${ }^{1,8}$

Veterans Health Administration (VHA) is committed to providing high-quality care and addressing disparities in health outcomes for vulnerable Veterans. ${ }^{9}, 10$ VHA Office of Patient Care Services-Population Health Services, and VHA Office of Rural Health (hereafter, VHA partners) requested an evidence review of social determinants of health for Veterans, to help develop policy for healthcare services which may be influenced by social determinants. Veterans enrolled in VHA services are more medically complex, have lower physical and mental health functioning, and have lower socioeconomic resources, as compared with either non-Veterans or Veterans not engaged in VHA care. ${ }^{1-13}$ Our VHA partners were especially interested in understanding whether certain social determinants may help explain differences in health outcomes between Veterans and 
non-Veterans, or between certain groups of Veterans (e.g., engaged or not engaged in VHA services).

Here, we present results from a larger evidence report ${ }^{14}$ prepared by the VA Evidence-based Synthesis Program (ESP) in response to our VHA partners, as noted above. We first developed evidence maps 15,16 to describe the existing literature on how social determinants may contribute to differences in health behaviors, health services utilization, and health outcomes for Veterans vs non-Veterans, and Veterans engaged vs nonengaged in VHA care. We used these maps to engage our VHA partners in a prioritization process, leading to the selection of four high-priority social determinants for more detailed review and qualitative syntheses-rurality, trauma exposure, sexual orientation, and gender identity.

\section{METHODS}

The protocol for this evidence review is registered at PROSPERO, no. CRD42017060165. ${ }^{17}$

\section{Conceptual Frameworks and Key Questions}

In collaboration with our VHA partners, we developed conceptual and analytic frameworks of the relationships between social determinants, Veteran experiences, health behaviors, health services utilization, and health outcomes (online Appendix Figure and ${ }^{14}$ ). We reviewed prior work from the MacArthur Research Network on Socioeconomic Status and Health ${ }^{18}$ and the Institute of Medicine (now National Academy of Medicine). ${ }^{1}$ We also considered whether particular social determinants were more likely relevant for Veterans' health. We were primarily concerned with social determinants as mediators of the effects of Veteran experiences, but recognized at the outset that there may not be many studies which used appropriate analytic tests of mediation. Therefore, we planned to include articles that only compared prevalence, levels, and/or characteristics of social determinants between our groups of interest (e.g., Veterans vs. non-Veterans), as these may still indicate whether certain social determinants are particularly important for VHA policy and deserve further attention from VHA research. We developed the following key questions (KQ):

KQ1 and KQ2-For Veterans compared with nonVeterans, are there differences in prevalence and/or characteristics of social determinants (KQ1), and does such variation account for differences in health behaviors, health services utilization, and/or health outcomes (KQ2)?

KQ3 and KQ4 -For engaged (i.e., enrolled in or utilizing categories of VHA services or benefits) compared with nonengaged Veterans, are there differences in prevalence and/or characteristics of social determinants (KQ3), and does such variation account for differences in health behaviors, health services utilization, and/or health outcomes (KQ4)?

\section{Search Strategy and Article Selection}

MEDLINE (OVID), CINAHL, PsycINFO, and Sociological Abstracts were searched from the date of inception to January 2017 (see online Appendix Table 1 and $^{14}$ for detailed search strategies). We also included references (1) referred by expert peer reviewers; (2) associated with large national observational cohorts or cross-sectional surveys (e.g., American Community Survey); and (3) associated with large VA studies and programs (e.g., National Center for Veterans Analysis and Statistics). We considered gray literature (e.g., white papers and presentations), but found this did not add substantially to evidence from peerreviewed, published articles; moreover, these sources frequently lacked sufficient information to assess quality. We also conducted a MEDLINE search with the same terms for Veterans and social determinants, but targeted to clinical trials instead of other study designs. We thought it unlikely that controlled clinical trials would address social determinants, but we carried out this additional search for completeness.

Citation/abstract screening was undertaken by $1-2$ independent reviewers, with exclusion requiring consensus of both reviewers. Two independent reviewers conducted full-text review and discrepancies were resolved by discussion or referred to a third reviewer. Eligible English-language articles met the following criteria: (1) compared Veterans vs nonVeterans, and/or engaged vs non-engaged Veterans; (2) addressed at least one social determinant; (3) $\geq 100$ participants; and (4) had eligible study design (e.g., cohort or crosssectional study) (see Online Appendix Table 2 for detailed criteria). We also required valid comparison groups for social determinants (e.g., rural and non-rural participants); studies with only participants sharing a social determinant (e.g., all rural residents) were not considered as addressing comparisons for that social determinant.

We performed citation/abstract screening, full-text review, and data abstraction in DistillerSR, (https://www.evidencepartners.com/products/distillersr-systematic-review-software/ accessed 5 July 2017).

\section{Data Abstraction, Quality Assessment, and Qualitative Synthesis}

Evidence maps: For all included articles $(N=131)$, we abstracted study design (e.g., cross-sectional or cohort); social determinants addressed; and whether analyses examined the role of social determinants in health behaviors, health services utilization, or health outcomes of interest.

Focused review and qualitative synthesis: For articles $(N=37)$ which investigated at least one of the four selected social determinants (i.e., rurality, trauma exposure, sexual orientation, and gender identity), we additionally abstracted data source(s); participant number and demographics; measure(s) of social determinant(s); the prevalence, degree, or level of social determinant(s) for the groups of interest (i.e., Veterans and non- 
Veterans, and/or engaged and non-engaged Veterans); and, if provided, the role of social determinants in health behaviors, health services utilization, and/or health outcomes. One reviewer completed data abstraction with verification by a second reviewer. Discrepancies were resolved by discussion between reviewers.

Two reviewers independently conducted quality assessments of included articles, with discrepancies resolved by discussion. We considered the following elements related to study quality:

(1) Representativeness and coverage (i.e., nationally representative sample, recruitment and selection, and concerns about missing data)

(2) Measurement (i.e., social determinants and outcomes assessed in similar manner for groups being compared and using standardized measures)

(3) Funding source (i.e., potential for bias).

Given substantial heterogeneity of published articles and very limited evidence addressing these social determinants, quantitative synthesis was not appropriate. We rated overall strength of evidence as high, moderate, low, or insufficient, per Owens et al. ${ }^{19}$ We considered precision (degree of certainty in estimates), consistency (direction of differences across included articles), directness (whether evidence links social determinants directly to outcomes of interest), and individual article quality (as described above).

\section{RESULTS}

\section{Evidence Map}

We screened 7242 abstracts, full-text reviewed 456 articles, and included 131 eligible articles (Fig. 1). ${ }^{20-150}$ Overall, most articles addressed classic socioeconomic factors, such as education, income, and employment; a substantial number of these articles examined the role of these factors in health outcomes, particularly for Veterans and non-Veterans, but fewer looked at health behaviors and health services utilization (Fig. 2, online Appendix Tables 3 and 4). For some social determinants, published evidence was lacking (e.g., sexual orientation and gender identity) (Fig. 2, online Appendix Tables 3 and 4). Ninety-nine articles addressed social determinants for Veterans and non-Veterans, and 40 articles for engaged and non-engaged Veterans. Most articles used cross-sectional data and included over 1000 participants (online Appendix Tables 3 and 4).

\section{Qualitative Synthesis of Evidence on Rurality, Trauma, and Sexual Orientation}

Twenty articles examined rurality, 17 addressed trauma, and 2 were on sexual orientation; no articles addressed gender identity. Most articles on rurality, trauma, and sexual orientation used nationally representative datasets, included more than 5000 participants, and were rated low or medium quality

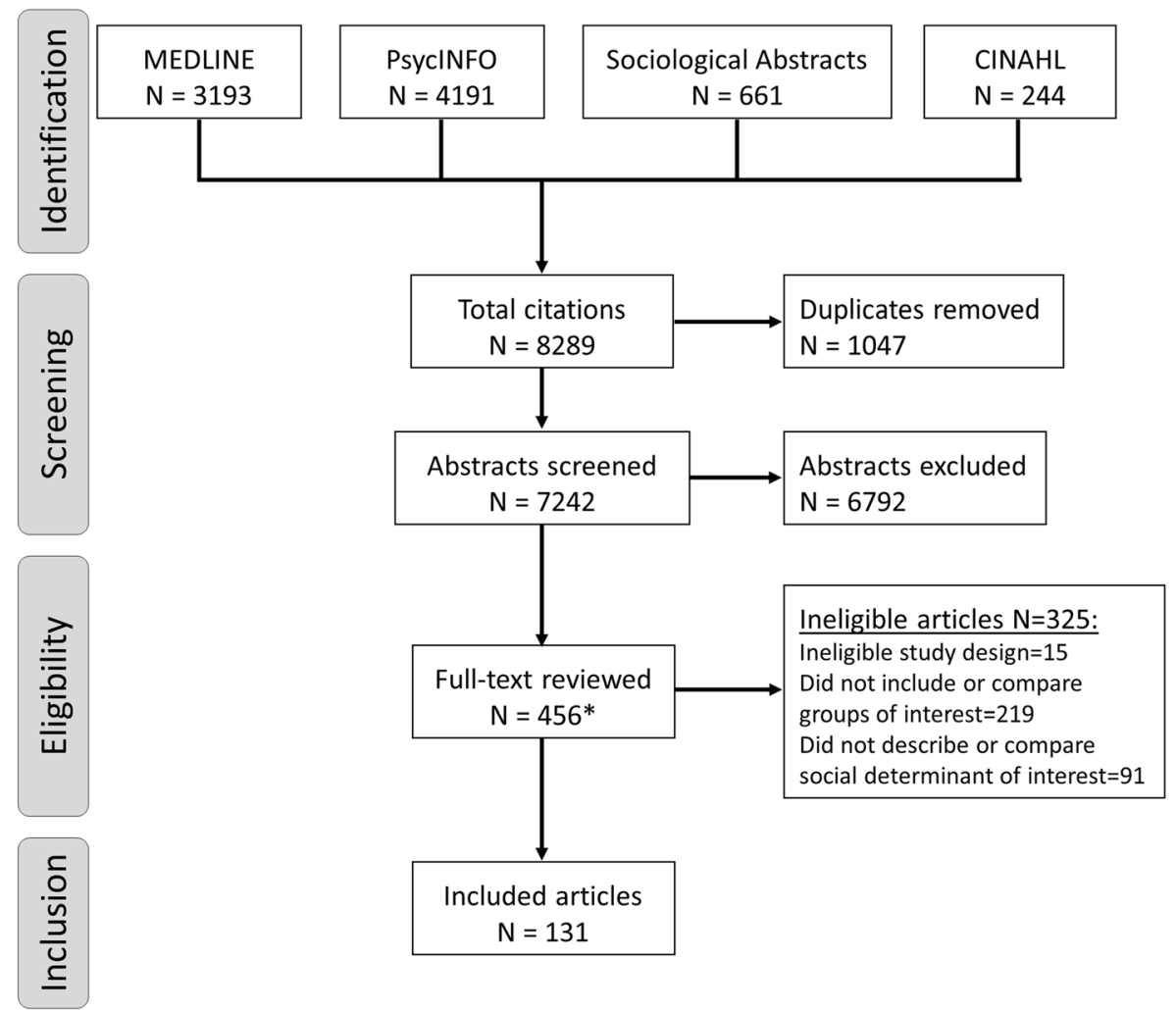

Figure 1 Citation screening and selection of included articles. Asterisk symbol indicates total articles reviewed includ an additional three articles found through an expedited review of MEDLINE citations $(N=354)$ identified using the same search terms except limited to trials, one article found through review of publications from the VA Epidemiology Program, and two articles recommended by expert reviewers. 

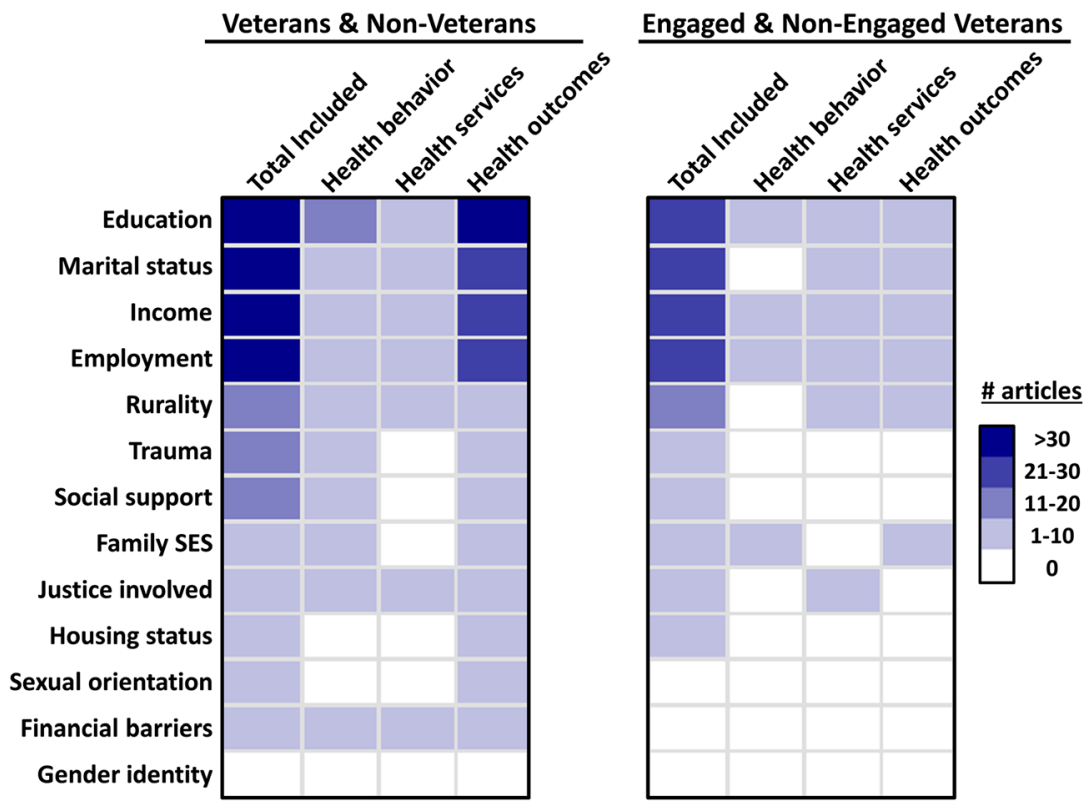

Figure 2 Heatmaps of included articles addressing social determinants and various outcomes for Veterans vs. non-Veterans, and for engaged vs. non-engaged Veterans. Articles may have addressed more than one social determinant, included comparisons of Veterans vs. non-Veterans and/ or engaged vs. non-engaged Veterans, and may or may not have examined the role of social determinants in health behaviors, services access, and/or various health outcomes. Of 131 total included articles, 99 compared Veterans with non-Veterans, and 40 articles addressed engaged and non-engaged Veterans. SES, socioeconomic status.

(Table 1). More than half of articles included only men or only women. Less than half of articles on rurality and trauma examined health behaviors, health services access or utilization, or health outcomes. One of two articles on sexual orientation addressed mortality risk.

\section{Rurality}

We found moderate strength of evidence indicating no or very small differences in the proportion of Veterans and nonVeterans who reside in rural areas. Articles comparing Veterans with non-Veterans used different rurality measures, including Metropolitan Statistical Areas (MSA), 21, 99, 106, 138, 140, 150 self-reported rural/urban residence, ${ }^{33,}$ 70, 76 and Rural-Urban Continuum (RUC) codes $^{137}$ (online Appendix Table 5). Most articles reported no differences in rural residence between Veterans and non-Veterans, although actual estimates varied widely (e.g., $18-47 \%$ of Veterans with rural or nonmetropolitan residences). This was likely due to differences in rurality definition, participant demographics (e.g., age and sex), and study timeframes (range 1986-2012). Only one article reported higher rural residence in Veterans, ${ }^{84}$ and one found lower rurality in Veterans ${ }^{99}$; both were low quality (Table 2).

We found insufficient evidence for the effects of rurality on differences in health behaviors, health services utilization, or health outcomes between Veterans and non-Veterans. While no articles examined the role of rurality in health behaviors, two medium-quality articles addressed utilization (Table 2). One article reported no differences between metropolitan and
Table 1 Summary of Characteristics of Included Articles for Rurality and Trauma

\begin{tabular}{|c|c|c|c|c|}
\hline & \multicolumn{2}{|c|}{$\begin{array}{l}\text { Veterans and } \\
\text { non-Veterans }\end{array}$} & \multicolumn{2}{|c|}{$\begin{array}{l}\text { Engaged and } \\
\text { non-engaged }\end{array}$} \\
\hline & Rurality & Trauma & Rurality & Trauma \\
\hline $\begin{array}{l}\text { Total number of } \\
\text { articles }\end{array}$ & 11 & 11 & 14 & 6 \\
\hline $\begin{array}{l}\text { Nationally } \\
\text { representative dataset }\end{array}$ & 9 & 6 & 12 & 2 \\
\hline Exclusively men & 5 & 2 & 2 & - \\
\hline \multicolumn{5}{|c|}{ Number of participants* } \\
\hline $100-1000$ & 1 & 3 & 2 & 4 \\
\hline $1001-5000$ & 3 & 2 & 2 & 2 \\
\hline$>5000$ & 6 & 6 & 9 & - \\
\hline \multicolumn{5}{|l|}{ Quality } \\
\hline Low & 4 & 5 & 4 & 4 \\
\hline Medium & 6 & 5 & 8 & 2 \\
\hline High & 1 & 1 & 2 & - \\
\hline \multicolumn{5}{|c|}{ Examined role of social determinant in } \\
\hline Health behaviors & - & 5 & - & - \\
\hline $\begin{array}{l}\text { Health services } \\
\text { access/utilization }\end{array}$ & 2 & - & 2 & - \\
\hline Mental health & 3 & 3 & 1 & - \\
\hline General health & 1 & 1 & 1 & - \\
\hline Mortality & - & 1 & - & - \\
\hline $\begin{array}{l}\text { Other health } \\
\text { outcomes }\end{array}$ & 1 & 1 & 1 & - \\
\hline
\end{tabular}

Articles may have addressed more than one social determinant, and may or may not have examined the role of social determinants in health behaviors, health services access, and/or various health outcomes. There were also two included articles ${ }^{87,89}$ on sexual orientation both compared Veterans and non-Veterans, using data from national cohorts, included only women, had more than 1000 participants, and were medium quality; one of these examined the role of sexual orientation on mortality and also addressed trauma exposure ${ }^{89}$

*Number of participants unclear in one article on rurality ${ }^{21}$ 
Table 2 Summary of Results Reported by Included Articles on Rurality, Trauma, and Sexual Orientation

\begin{tabular}{|c|c|c|c|c|c|c|}
\hline & \multirow{3}{*}{ Category } & \multirow{3}{*}{ Results description } & \multicolumn{4}{|c|}{ Number of articles reporting results } \\
\hline & & & \multicolumn{2}{|c|}{$\begin{array}{l}\text { Veterans and non- } \\
\text { Veterans }\end{array}$} & \multicolumn{2}{|c|}{ Engaged and non-engaged } \\
\hline & & & $\begin{array}{l}\text { Low } \\
\text { quality }\end{array}$ & $\begin{array}{l}\text { Medium or } \\
\text { high quality }\end{array}$ & $\begin{array}{l}\text { Low } \\
\text { quality }\end{array}$ & $\begin{array}{l}\text { Medium or } \\
\text { high quality }\end{array}$ \\
\hline \multirow[t]{10}{*}{ Rurality } & \multirow[t]{4}{*}{ Prevalence } & No difference* & 2 & 6 & 3 & 5 \\
\hline & & Higher for Veterans/engaged & 1 & - & - & 1 \\
\hline & & Higher for non-Veterans/non-engaged & 1 & - & 1 & 2 \\
\hline & & Mixed or unclear results & - & 1 & - & 2 \\
\hline & Health behaviors & & - & - & - & - \\
\hline & Health services & Rurality associated with lower utilization & - & 1 & - & 1 \\
\hline & access/utilization & Mixed or unclear results & - & 1 & _- & 1 \\
\hline & \multirow{3}{*}{ Health outcomes } & No association of rurality with general health & - & 1 & - & 1 \\
\hline & & No association of rurality with mental health & - & 3 & - & 1 \\
\hline & & $\begin{array}{l}\text { No association of rurality with risk of } \\
\text { hospitalization due to ambulatory care sensitive } \\
\text { conditions }\end{array}$ & - & 1 & - & 1 \\
\hline \multirow{14}{*}{$\begin{array}{l}\text { Trauma } \\
\text { exposure }\end{array}$} & \multirow[t]{3}{*}{ Prevalence } & No difference* & 2 & - & - & 1 \\
\hline & & Higher for Veterans/engaged & - & 4 & 4 & 1 \\
\hline & & Higher for non-Veterans/non-engaged & 3 & 1 & - & - \\
\hline & \multirow[t]{6}{*}{ Health behaviors } & Trauma associated with more smoking & - & 3 & - & - \\
\hline & & Trauma associated with more heavy drinking & - & 2 & - & - \\
\hline & & Unclear association with heavy drinking & - & 1 & - & - \\
\hline & & Unclear association with lack of exercise & - & 1 & - & - \\
\hline & & No association with drug use & 1 & - & _- & - \\
\hline & & $\begin{array}{l}\text { Accounting for trauma reduced association of } \\
\text { Veteran status with more smoking }\end{array}$ & - & 1 & - & - \\
\hline & \multirow{5}{*}{$\begin{array}{l}\text { Health services } \\
\text { access/utilization } \\
\text { Health outcomes }\end{array}$} & & - & - & - & - \\
\hline & & Trauma associated with more depression & - & 2 & - & - \\
\hline & & $\begin{array}{l}\text { Trauma associated with worse general health, } \\
\text { days of poor physical health, and days of poor } \\
\text { mental health }\end{array}$ & - & 1 & - & - \\
\hline & & $\begin{array}{l}\text { Accounting for trauma reduced association of } \\
\text { Veteran status with greater disability }\end{array}$ & - & 1 & - & - \\
\hline & & Unclear association with mortality risk & _- & 1 & - & - \\
\hline \multirow{4}{*}{$\begin{array}{l}\text { Sexual } \\
\text { orientation }\end{array}$} & \multirow{4}{*}{$\begin{array}{l}\text { Prevalence } \\
\text { health behaviors } \\
\text { Health services } \\
\text { access/utilization } \\
\text { Health outcomes }\end{array}$} & No difference* & - & 2 & - & - \\
\hline & & & - & - & - & - \\
\hline & & & - & - & - & - \\
\hline & & $\begin{array}{l}\text { Sexual minority status associated with higher } \\
\text { risk for all-cause mortality }\end{array}$ & - & 1 & - & - \\
\hline
\end{tabular}

Articles may have addressed more than one social determinant, and may or may not have examined the role of social determinants in health behaviors, health services access, and/or various health outcomes

*Non-significant difference or if no statistical testing, $<5 \%$ difference

non-metropolitan participants in proportion having a "checkup" within the prior 2 years. ${ }^{137}$ The other article examined associations with total healthcare expenditures and found significant interaction effects between rural residence and a combined Veteran/VHA-user categorical variable (i.e., nonVeteran, Veteran VHA user, and Veteran non-VHA user); the magnitude of interaction effects was not reported. ${ }^{138}$ Three medium-quality articles investigated a variety of health outcomes, ${ }^{106,137,140}$ and none found significant associations for either Veteran status or rurality (Table 2 ).

We found moderate strength of evidence indicating no or very small differences in the proportion of engaged and non-engaged Veterans who reside in rural areas. Articles including engaged and non-engaged Veterans also employed varying measures of rurality, including MSA, ${ }^{21,55,138}$ self-reported rural/urban residence, ${ }^{70,} 107$, 120 RUC codes, ${ }^{81,} 137$ Rural-Urban Commuting Area (RUCA) codes, ${ }^{26,47,48}$ and straight-line distances between participant homes and nearest VHA facility ${ }^{98}$ (online Appendix Table 6). More than half of articles reported no difference in rural residence between engaged and non-engaged Veterans (actual estimates 6-26\%). ${ }^{47,48,}$ $55,70,73,107,120,138$ One medium-quality article found slightly higher rurality for engaged Veterans (30 vs $24 \%$ of non-engaged). ${ }^{137}$ In contrast, another medium-quality article reported lower rural residence in engaged Veterans ( $18 \%$ engaged vs $28 \%$ non-engaged), but was limited to Native Americans enrolled in VHA and Indian Health Service. ${ }^{81}$ One high-quality article used VHA administrative data and showed lower rural residence for Veterans using VHA homeless services ( $15 \%$ engaged vs $21 \%$ nonengaged). ${ }^{26}$

We found insufficient evidence for the effects of rurality on differences in health behaviors, health services utilization, or health outcomes between engaged and non-engaged Veterans. No articles examined health behaviors, but two mediumquality articles addressed utilization ${ }^{137,138}$ (Table 2). Both of these articles defined engaged as self-reported VHA 
utilization, with one finding that rurality was associated with lower rate of check-ups ${ }^{137}$ and the other reporting significant interactions between rurality and Veteran/engaged status, as described above. ${ }^{138}$ Two medium-quality articles investigated health outcomes, and found no association between rurality and general or mental health, ${ }^{137}$ or with hospitalizations due to ambulatory care-sensitive conditions (21) (Table 2).

\section{Trauma}

We found low strength of evidence that there is a higher prevalence of trauma exposure among Veterans, as compared with non-Veterans. Articles comparing Veterans and nonVeterans used different measures to assess different trauma types (online Appendix Table 5). Six articles examined adverse childhood experiences ${ }^{29}, 60,77,100,103,118,145$ and the Adverse Childhood Experiences scale (ACEs) was the most commonly used measure. ${ }^{29,} 77,100$ All three articles using ACEs employed Behavioral Risk Factor Surveillance System (BRFSS) data, which included an ACEs module in multiple years. One article reported whether respondents had been "victimized" in the prior 12 months. ${ }^{139}$ Four articles examined adult experience of sexual trauma or intimate partner violence (IPV), ${ }^{34,60,103,118}$ while two examined adult physical trauma. ${ }^{89,} 103$ Only one article examined combat-related trauma. ${ }^{103}$ Prevalence estimates were inconsistent across articles, with six finding higher prevalence among Veterans, ${ }^{29}, 41,77$, $103,118,139$ three finding lower prevalence among Veterans, ${ }^{34}$, 60, 89 and two finding no difference in prevalence between Veterans and non-Veterans. ${ }^{100,} 145$ Inconsistencies were likely due to a broad range of historical periods and cohorts being studied (i.e., Vietnam era through wars in Iraq and Afghanistan), and differences in age, sex, race/ethnicity, and other key participant characteristics (online Appendix Table 5). One article included only homeless smokers. ${ }^{60}$

There was low strength of evidence that trauma exposure contributes to differences in prevalence of smoking between Veterans and non-Veterans, and insufficient evidence for the role of trauma in health services utilization and health outcomes. Four articles examined associations of trauma exposure with health behaviors, and most focused on smoking and

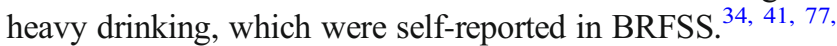
${ }^{100}$ Trauma exposure, whether IPV ${ }^{34,41}$ or ACEs, ${ }^{77,100}$ was associated with higher prevalence of current smoking (Table 2). Two of these articles also found a positive association between trauma exposure and heavy drinking. ${ }^{34,77}$ One article analyzed trauma exposure as moderating the association between Veteran status and health behaviors (i.e., smoking and heavy drinking), finding significant interaction effects between Veteran status and ACEs score for smoking, but no significant interaction for predicting heavy drinking. ${ }^{77}$ One article showed that trauma exposure may mediate the association between Veteran status and smoking - higher odds of smoking for Veterans compared with non-Veterans (adjusted odds ratio [AOR] 1.84 [95\% CI 1.18, 2.88]) were reduced after including ACEs scores (AOR 1.57 [95\% CI 0.96, 2.58]). ${ }^{100}$ Five articles ${ }^{34,41,77,89,100}$ examined a range of health outcomes, with two finding that trauma was positively associated with more depression, ${ }^{34,41}$ and one showing associations with worse general health, more days of poor physical health, and more days of poor mental health ${ }^{77}$ (Table 2). One article showed that trauma partially mediated associations between Veteran status and disability - accounting for ACEs scores reduced the higher odds of disability among Veterans compared with non-Veterans (AOR 1.83 [95\% CI 1.08, 3.10] without ACEs, and AOR 1.57 [95\% CI 0.90, 2.75] with ACEs included). ${ }^{100}$ One article examined risk for all-cause mortality, cancer-specific mortality, and cardiovascular disease-related mortality, finding inconsistent associations between trauma and these outcomes, in models accounting for Veteran status. ${ }^{89}$

We found low strength of evidence that there is a higher prevalence of trauma exposure among engaged vs nonengaged Veterans. Articles on engaged and non-engaged Veterans also employed different measures and studied various trauma exposures (online Appendix Table 6). One article examined adverse childhood experiences and adult experience of sexual trauma or IPV ${ }^{88}$ three articles addressed combatrelated trauma and sexual or non-combat-related physical trauma during military service, ${ }^{88,107,115}$ one article examined history of military sexual assault, ${ }^{59}$ and one article examined Vietnam war-zone service. ${ }^{52}$ One article investigated military trauma related to sexual minority status. ${ }^{120}$ Estimates of trauma prevalence were primarily unadjusted and mostly consistent across articles, with five articles finding higher prevalence among engaged Veterans, ${ }^{52,59,88,115,120}$ and one showing mostly no difference. ${ }^{107}$

No articles examined the role of trauma in health behaviors, health services utilization, or health outcomes for engaged and non-engaged Veterans.

\section{Sexual Orientation}

We found insufficient evidence on sexual orientation for Veterans and non-Veterans, and no articles compared engaged and non-engaged Veterans (Table 2). The two articles examining sexual orientation for Veterans and non-Veterans both used nationally representative data, had only women participants, and were medium quality (online Appendix Table 5). ${ }^{87,} 89$ One article used National Health and Nutrition Examination Survey data (1999-2010) and reported no significant difference in prevalence of non-heterosexual orientation (7\% Veterans vs $5 \%$ non-Veterans); no health behaviors, health services utilization, or health outcomes were examined. ${ }^{87}$ The other article used data from the Women's Health Initiative and found more Veterans identified as sexual minorities (i.e., non-heterosexual) compared to non-Veterans (4 vs 1\%). ${ }^{89}$ In adjusted analyses, sexual minority status and Veteran status were independently associated with increased risk for all-cause mortality. ${ }^{89}$ Interaction effects were also examined for sexual minority status and 
Veteran status, in predicting mortality risk but these were largely insignificant. ${ }^{89}$ These two articles differed in study populations (e.g., mean age 40 years $^{87}$ vs 63 years ${ }^{89}$ ).

\section{DISCUSSION}

In this evidence review of social determinants impacting health behaviors, health services utilization, and health outcomes for Veterans, we found that most published articles examined classic sociodemographic characteristics. A smaller set of published articles addressed factors, such as rurality and trauma. Few or no studies addressed the remaining group of emerging social determinants, including sexual orientation and gender identity. Often, even when there was substantial published literature for certain social determinants, gaps remained due to lack of studies examining how social determinants actually affected health behaviors, healthcare utilization, and/or health outcomes.

We found little to no evidence on the roles of rurality and trauma exposure on health behaviors, health services utilization, and health outcomes, whether comparing Veterans vs non-Veterans or engaged vs non-engaged Veterans. Given this lack of evidence, existing literature on the impact of these factors in the general population can help guide policy for Veterans. Numerous challenges and health disparities affecting rural US communities have been demonstrated ${ }^{151}$; Veterans in rural settings likely face similar resource limitations, access barriers, and risk factors. Similarly, there are substantial health consequences of trauma exposures for the general adult population, ${ }^{152}$ which should inform policy and planning for Veterans. For example, VHA could improve standardized assessment for exposures, develop strategies for providing traumasensitive care, and consider targeted efforts to prevent negative impacts associated with poor health behaviors (e.g., smoking). Since some types of trauma exposure precede military service, it may also be beneficial to develop assessment and strategies at the time of enlistment.

We found insufficient evidence for both sexual orientation and gender identity. Challenges to addressing these factors include cultural stigma and lack of standardized assessment in many current national datasets.

The VHA Blueprint for Excellence ${ }^{153}$ outlines several essential strategies for improving services and enhancing Veteran health, including addressing the needs of vulnerable Veterans and delivering personalized, patientcentered care (e.g., considering relevant social determinants). Our review supports systematic assessment for socioeconomic factors which have a robust literature and contribute to health disparities. ${ }^{1,7}$ For social determinants with more limited evidence specifically for Veterans, such as rurality and trauma exposure, we suggest that current evidence gaps should not preclude the development of VHA policies to address probable challenges and health impacts of these factors for Veterans. For social determinants with little to no evidence, such as sexual orientation and gender identity, VHA should support development of consistent, accurate measures within VHA, and advocate for inclusion of these measures in ongoing large national surveys on health and behavior. Integration of VHA data with existing non-VHA data sources could also help us compare the impact of social determinants on Veterans engaged and not engaged in VHA services.

Our review highlights certain challenges in examining the role of social determinants in health. First, measures for rurality and trauma exposure often encompassed conceptually related but distinct aspects within these broader constructs. Rural communities are defined not just by distance and population density, but also by social connections, cultural norms, and attitudes. ${ }^{154}$ To address health disparities for rural Veterans, we need direct measures of those aspects relevant to health. Similarly, although a variety of adverse circumstances and traumatic events could plausibly affect Veterans' health, failing to make conceptually important distinctions in types of trauma leads to challenges in defining those key relationships that could be targeted to improve health outcomes. Second, per our conceptual model (online Appendix Figure), relationships involving social determinants are likely bidirectional and dynamic over the lifespan. For example, education can affect selection into the military, and military service could in turn impact educational attainment (e.g., military training or as benefits for Veterans). ${ }^{155} \mathrm{In}$ the current era of service without conscription, social determinants may have even stronger effects on selection into the military and the nature of military experiences. One article highlighted this complexity by showing that for men in the current era, there was greater childhood adversity for Veterans compared with non-Veterans, but this was not true when comparing men who would have served during the draft era. ${ }^{29}$ Future studies should address selection effects of social determinants and other mechanisms that predate military service.

Our evidence review has several limitations. We excluded articles if they did not compare our populations of interest; thus, our results do not imply that evidence did not exist for the general population. Publication bias may have affected our results if articles were less likely to be published when results showed no impact of social determinants on health. Finally, although we aimed to be broad and inclusive in conducting our review, our final search and selection focused on social determinants of high interest to our VHA partners.

In conclusion, we found limited to no evidence on certain emerging social determinants. We found no differences in rural residence between our groups of interest; trauma exposure was higher in Veterans (vs non-Veterans) and Veterans engaged in VHA care (vs non-engaged). We found insufficient 
evidence on sexual orientation and gender identity. We recommend consistent measures for social determinants, clear conceptual frameworks, and analytic strategies that account for the complex relationships between social determinants, Veteran experiences, and health.

Corresponding Author: Wei Duan-Porter, MD, PhD; Center for Chronic Disease Outcomes Research Minneapolis VA Health Care System HSR\&D, One Veterans Dr, Minneapolis, MN 55417, USA (e-mail: wei.duanporter@va.gov).

Funders This work was supported by VA Quality Enhancement Research Initiative (QUERI) funding for ESP (VA-ESP Project No.09009; 2017). The funder had no role in study design, data collection, analysis and interpretation of data, writing of the report, or decision to submit article for publication.

\section{Compliance with Ethical Standards:}

Conflict of Interest: The authors declare that they do not have a conflict of interest.

\section{REFERENCES}

1. Institute of Medicine. Capturing social and behavioral domains and measures in electronic health records: phase 2. Washington DC: The National Academies Press; 2014.

2. Tarlov AR. Public policy frameworks for improving population health. Annals of the New York Academy of Sciences. 1999; 896(1):281-93.

3. Marmot MG, Shipley MJ, Rose G. Inequalities in death-specific explanations of a general pattern? The Lancet. 1984; 323 (8384):1003-6.

4. Marmot MG, Stansfeld S, Patel C, North F, Head J, White I, et al Health inequalities among British civil servants: the Whitehall II study. The Lancet. 1991; 337 (8754):1387-93.

5. Phelan JC, Link BG, Tehranifar P. Social conditions as fundamental causes of health inequalities: theory, evidence, and policy implications. Journal of health and social behavior. 2010; 51 (1_suppl):S28-S40.

6. Adler NE, Stewart J. Health disparities across the lifespan: meaning, methods, and mechanisms. Ann NY Acad Sci. 2010; 1186:5-23.

7. Adler NE, Glymour MM, Fielding $\mathbf{J}$. Addressing social determinants of health and health inequalities. JAMA. 2016; 316 (16):1641-2. doi:https://doi.org/10.1001/jama.2016.14058

8. Washington AE, Coye MJ, Boulware LE. Academic health systems third curve: population health improvement. JAMA. 2016; 315(5):45960. doi:https://doi.org/10.1001/jama.2015.18550

9. VHA Office of Health Equity. https://www.va.gov/healthequity/. Accessed June 7, 2018.

10. VHA Patient care services-LGBT care. https://www.patientcare.va. gov/LGBT/. Accessed June 7, 2018.

11. Agha Z, Lofgren RP, VanRuiswyk JV, Layde PM. Are patients at Veterans Affairs medical centers sicker? A comparative analysis of health status and medical resource use. Arch Intern Med. 2000; 160(21):3252-7.

12. Selim AJ, Berlowitz DR, Fincke G, Cong Z, Rogers W, Haffer SC, et al. The health status of elderly veteran enrollees in the Veterans Health Administration. J Am Geriatr Soc. 2004; 52(8): 1271-6. doi:https://doi. org/10.1111/j.1532-5415.2004.52355.x

13. Tsai J, Rosenheck RA. Use of the internet and an online personal health record system by US veterans: comparison of Veterans Affairs mental health service users and other veterans nationally. J Am Med Inform Assoc. 2012; 19(6):1089-94. doi:https://doi.org/10.1136/ amiajnl-2012-000971

14. Duan-Porter W, Martinson BC, Taylor BC, Falde S, Gnan K, Greer N et al. ESP evidence review: social determinants of health for veterans.
2017. https://www.hsrd.research.va.gov/publications/esp/socialdeterminants.cfm. Accessed June 7, 2018.

15. Bragge P, Clavisi O, Turner T, Tavender E, Collie A, Gruen RL. The Global Evidence Mapping Initiative: scoping research in broad topic areas. BMC Med Res Methodol. 2010;11:92

16. Ryan RE, Kaufman CA, Hill SJ. Building blocks for meta-synthesis: data integration tables for summarising, mapping, and synthesising evidence on interventions for communicating with health consumers. BMC Med Res Methodol. 2009;9:16.

17. Social determinants of health for Veterans-PROSPERO protocol. https://www.crd.york.ac.uk/prospero/display_record.php? RecordID=60165. Accessed June 7, 2018.

18. MacArthur Research Network on SES \& Health. http://www.macses. ucsf.edu/. Accessed June 7, 2018.

19. Owens DK, Lohr KN, Atkins D, Treadwell JR, Reston JT, Bass EB, et al. AHRQ series paper 5: grading the strength of a body of evidence when comparing medical interventions-Agency for Healthcare Research and Quality and the Effective Health-Care Program. Journal of clinical epidemiology. 2010;63(5):513-23.

20. Abraham KM, Ganoczy, D.,Yosef, M.,Resnick, S. G.,Zivin, K. Receipt of employment services among Veterans Health Administration users with psychiatric diagnoses. Journal of Rehabilitation Research \& Development. 2014;51

21. Ajmera M, Wilkins, T. L.,Sambamoorthi, U. Dual Medicare and Veteran Health Administration use and ambulatory care sensitive hospitalizations. Journal of General Internal Medicine. 2011;26 Suppl 2.

22. Baldwin CM, Long, K.,Kroesen, K.,Brooks, A.J.,Bell, I. R. A Profile of military Veterans in the Southwestern United States who use complementary and alternative medicine. Archives of Internal Medicine. $2002 ; 162$.

23. Bareis N, Mezuk, Briana. The relationship between childhood poverty, military service, and later life depression among men: evidence from the Health and Retirement Study. Journal of Affective Disorders. 2016;206.

24. Barrera TL, Cully, Jeffrey A., Amspoker, Amber B., Wilson, Nancy L., Kraus-Schuman, Cynthia, Wagener, Paula D., Calleo, Jessica S., Teng, Ellen J., Rhoades, Howard M., Masozera, Nicholas, Kunik, Mark E., Stanley, Melinda A. Cognitive-behavioral therapy for late-life anxiety: similarities and differences between Veteran and community participants. Journal of Anxiety Disorders. 2015;33.

25. Bastian LA, MD, MPH, Gray, Kristen E, PhD, MS,DeRycke, Eric, MPH,Mirza, Shireen, MD, Gierisch, Jennifer M, PhD, MPH,Haskell, Sally G, MD, MS,Magruder, Kathryn M, PhD,Wakelee, Heather A, MD,Wang, Ange, BSE,Ho, Gloria Y F, PhD, MPH,LaCroix, Andrea Z, PhD. Differences in active and passive smoking exposures and lung cancer incidence between veterans and non-veterans in the Women's Health Initiative. The Gerontologist. 2016;56.

26. Blackstock OJ, Haskell, Sally G., Brandt, Cynthia A., Desai, Rani A. Gender and the use of veterans health administration homeless services programs among Iraq/Afghanistan veterans. Medical Care. 2012;50.

27. Blosnich J, Foynes, Melissa Ming,Shipherd, Jillian C. Health disparities among sexual minority women veterans. Journal of Women's Health. 2013;22.

28. Blosnich J, Bossarte, R.,Silver, E.,Silenzio, v. Health care utilization and health indicators among a national sample of U.S. veterans in same-sex partnerships. Military Medicine. 2013;178.

29. Blosnich JR, Dichter, Melissa E.,Cerulli, Catherine, Batten, Sonja V., Bossarte, Robert M. Disparities in adverse childhood experiences among individuals with a history of military service. JAMA Psychiatry. 2014;71.

30. Bohnert ASB, Ilgen, Mark A., Bossarte, Robert M., Britton, Peter C., Chermack, Stephen T., Blow, Frederic C. Veteran status and alcohol use in men in the United States. Military Medicine. 2012;177.

31. Bookwala J, Frieze, Irene H., Grote, Nancy. The long-term effects of military service on quality of life: the Vietnam experience. Journal of Applied Social Psychology. 1994;24.

32. Boscarino JA, Sitarik, A.,Gordon, S. C.,Rupp, L. B.,Nerenz, D. R.,Vijayadeva, V.,Schmidt, M. A.,Henkle, E., Lu, M. Risk factors for hepatitis $\mathrm{C}$ infection among Vietnam era veterans versus nonveterans: results from the Chronic Hepatitis Cohort Study (CHeCS). Journal of Community Health. 2014;39.

33. Brown C, Routon, P Wesley. Military service and the Civilian Labor Force: time- and income-based evidence. Armed Forces and Society. 2016;42.

34. Cerulli C, Bossarte, Robert M., Dichter, Melissa E. Exploring intimate partner violence status among male veterans and associated health outcomes. American Journal of Men's Health. 2014;8. 
35. Chi RC, Reiber, G. E.,Neuzil, K. M. Influenza and pneumococcal vaccination in older veterans: results from the behavioral risk factor surveillance system. Journal of the American Geriatrics Society. 2006;54.

36. Cordray SM, Polk, Kenneth R, Britton, Brandy M. Premilitary antecedents of post-traumatic stress disorder in an Oregon Cohort Journal of Clinical Psychology. 1992;48.

37. Cowper DC, Longino, Charles F, Jr, Kubal, Joseph D, Manheim, Larry M, Dienstfrey, Stephen J, Palmer, Jill M. The retirement migration of U.S. Veterans, 1960, 1970, 1980, and 1990. Journal of Applied Gerontology. 2000;19.

38. Culp R, Youstin, Tasha J, Englander, Kristin, Lynch, James. From war to prison: examining the relationship between military service and criminal activity. Justice Quarterly. 2013;30.

39. Currier JM, McDermott, Ryon C., Sims, Brook M. Patterns of helpseeking in a national sample of student veterans: a matched control group investigation. General Hospital Psychiatry. 2016;43.

40. De Luca SM, Blosnich, John R., Hentschel, Elizabeth A. W., King, Erika, Amen, Sally. Mental health care utilization: how race, ethnicity and veteran status are associated with seeking help. Community Mental Health Journal. 2016;52.

41. Dichter ME, Cerulli, Catherine, Bossarte, Robert M. Intimate partner violence victimization among women veterans and associated heart health risks. Women's Health Issues. 2011;21.

42. Dunne EM, Burrell, L. E., 2nd,Diggins, A. D.,Whitehead, N. E.,Latimer, W. W. Increased risk for substance use and health-related problems among homeless veterans. American Journal on Addictions. 2015;24.

43. Dursa EK, Bart, S.K.,Bossarte, R.M.,Schneiderman, A.I.,,. Demo graphic, Military, and Health characteristics of VA health care users and nonusers who served in or during operation enduring freedom or Operation Iraqi Freedom, 2009-2011. Public Health Reports. 2016;131.

44. Elder GH, Jr.,Shanahan, M. J.,Clipp, E. C. When war comes to men's lives: life-course patterns in family, work, and health. Psychology \& Aging. 1994;9.

45. Elhai JD, Frueh, B. Christopher, Gold, Paul B., Gold, Steven N., Hamner, Mark B. Clinical presentations of posttraumatic stress disorder across trauma populations: a comparison of MMPI-2 profiles of combat veterans and adult survivors of child sexual abuse. Journal of Nervous and Mental Disease. 2000; 188

46. Faestel PM, Littell, C. T.,Vitiello, M. V.,Forsberg, C. W.,Littman, A. J. Perceived insufficient rest or sleep among veterans: behavioral risk factor surveillance system 2009. Journal of Clinical Sleep Medicine. 2013;9.

47. French DD, Margo, Curtis E. Factors associated with the utilization of cataract surgery for veterans dually enrolled in Medicare. Military Medicine. 2012;177

48. French DD, Bradham, Douglas D., Campbell, Robert R., Haggstrom, David A., Myers, Laura J., Chumbler, Neale R., Hagan, Michael P. Factors associated with program utilization of radiation therapy treatment for VHA and medicare dually enrolled patients. Journal of Community Health: The Publication for Health Promotion and Disease Prevention. 2012;37.

49. Fulton LV, Belote, J. M.,Brooks, M. S., Coppola, M. N. A comparison of disabled veteran and nonveteran income: time to revise the law? Journal of Disability Policy Studies. 2009;20.

50. Gabrielian S, Yuan, Anita H., Andersen, Ronald M., Rubenstein, Lisa V., Gelberg, Lillian. VA health service utilization for homeless and lowincome veterans: a spotlight on the VA Supportive Housing (VASH) program in greater Los Angeles. Medical Care. 2014;52.

51. Gabrielian S, Burns, Alaina V.,Nanda, Nupur, Hellemann, Gerhard, Kane, Vincent, Young, Alexander S. Factors associated with premature exits from supported housing. Psychiatric Services. 2016;67.

52. Gamache G, Rosenheck, R. A.,Tessler, R. Factors predicting choice of provider among homeless veterans with mental illness. Psychiatric Services. 2000;51

53. Gamache G, Rosenheck, R.,Tessler, R. The proportion of veterans among homeless men: a decade later. Social Psychiatry \& Psychiatric Epidemiology. 2001;36.

54. Gfeller JD, Roskos, P. Tyler. A comparison of insufficient effort rates, neuropsychological functioning, and neuropsychiatric symptom reporting in military veterans and civilians with chronic traumatic brain injury. Behavioral Sciences \& the Law. 2013;31.

55. Gorman LA, Sripada, Rebecca K.,Ganoczy, Dara,Walters, Heather M., Bohnert, Kipling M., Dalack, Gregory W.,Valenstein, Marcia.
Determinants of national guard mental health service utilization in VA versus non?VA settings. Health Services Research. 2016;51.

56. Gould CE, Rideaux, Tiffany, Spira, Adam P., Beaudreau, Sherry A Depression and anxiety symptoms in male veterans and non?veterans: the Health and Retirement study. International Journal of Geriatric Psychiatry. 2015;30.

57. Greenberg GA, Rosenheck, Robert A, Desai, Rani A. Risk of incarceration among male Veterans and Nonveterans: are Veterans of the All Volunteer Force at greater risk? Armed Forces \& Society. 2007;33.

58. Grossbard JR, Lehavot, Keren, Hoerster, Katherine D., Jakupcak, Matthew, Seal, Karen H., Simpson, Tracy L. Relationships among veteran status, gender, and key health indicators in a national young adult sample. Psychiatric Services. 2013;64.

59. Hamilton AB, Frayne, S. M.,Cordasco, K. M.,Washington, D. L. Factors related to attrition from VA healthcare use: findings from the National Survey of Women Veterans. Journal of General Internal Medicine. 2013;28 Suppl 2 .

60. Hammett P, Fu, Steven S., Lando, Harry A., Owen, Greg, Okuyemi, Kolawale $\mathbf{S}$. The association of military discharge variables with smoking status among homeless Veterans. Preventive Medicine: An International Journal Devoted to Practice and Theory. 2015;81.

61. Hardy MA, PhD, Reyes, Adriana M, MA. The longevity legacy of World War II: the intersection of GI status and mortality. The Gerontologist. 2016;56

62. Hartley TA, Violanti, J. M.,Mnatsakanova, A. Andrew, M. E.,Burchfiel, C. M. Military experience and levels of stress and coping in police officers. International Journal of Emergency Mental Health. 2013;15.

63. Hedrick B, Pape, T. L.,Heinemann, A. W.,Ruddell, J. L.,Reis, J. Employment issues and assistive technology use for persons with spinal cord injury. Journal of Rehabilitation Research \& Development. 2006; 43 .

64. Henderson C, Bainbridge, Jay, Keaton, Kim, Kenton, Martha, Guz, Meghan, Kanis, Becky. The use of data to assist in the design of a new service system for homeless veterans in New York City. Psychiatric Quarterly. 2008;79.

65. Heslin KC, Guerrero, E. G.,Mitchell, M. N.,Afable, M. K.,Dobalian, A Explaining differences in hepatitis $\mathrm{C}$ between U.S. veterans and nonveterans in treatment for substance abuse: results from a regression decomposition. Substance Use \& Misuse. 2013;48.

66. Hisnanick JJ. Changes over time in the ADL status of elderly US veterans. Age \& Ageing. 1994;23

67. Hoerster KD, Lehavot, K.,Simpson, T.,McFall, M.,Reiber, G.,Nelson, K. M. Health and health behavior differences: U.S. Military, veteran, and civilian men. American Journal of Preventive Medicine. 2012;43.

68. Hoff RA, Rosenheck, Robert A. The use of VA and non-VA mental health services by female veterans. Medical Care. 1998;36.

69. Hoglund MW, Schwartz, Rebecca M. Mental health in deployed and nondeployed veteran men and women in Comparison with their civilian counterparts. Military Medicine. 2014;179.

70. Houston TK, Volkman, Julie E., Feng, Hua, Nazi, Kim M., Shimada, Stephanie L., Fox, Susannah. Veteran Internet use and engagement with health information online. Military Medicine. 2013;178.

71. Howren MB, Cai, Xueya, Rosenthal, Gary, Weg, Mark w. Vander. Associations of health-related quality of life with healthcare utilization status in veterans. Applied Research in Quality of Life. 2012;7.

72. Hoy-Ellis CP, $\mathbf{P h D}$, Shiu, Chengshi, $\mathbf{P h D}$, Sullivan, Kathleen $\mathbf{M}, \mathbf{P h D}$ Kim, Hyun-Jun, PhD, Sturges, Allison M, BA, Fredriksen-Goldsen, Karen I, PhD. Prior military service, identity stigma, and mental health among transgender older adults. The Gerontologist. 2017;57

73. Hynes DM, Koelling, K.,Stroupe, K.,Arnold, N.,Mallin, K.,Sohn, M. W.,Weaver, F. M.,Manheim, L.,Kok, L. Veterans' access to and use of Medicare and Veterans Affairs health care. Medical Care. 2007;45.

74. Johnson AM, Rose, K. M.,Elder, G. H., Jr.,Chambless, L. E.,Kaufman, J. S.,Heiss, G. Military combat and burden of subclinical atherosclerosis in middle aged men: the ARIC study. Preventive Medicine. 2010;50.

75. Johnson AM, Rose, K. M.,Elder, G. H., Jr.,Chambless, L. E.,Kaufman, J. S.,Heiss, G. Military combat and risk of coronary heart disease and ischemic stroke in aging men: the Atherosclerosis Risk in Communities (ARIC) study. Annals of Epidemiology. 2010;20.

76. Kaplan MS, Huguet, Nathalie, McFarland, Bentson H., Newsom, Jason T. Suicide among male veterans: a prospective population-based study. Journal of Epidemiology and Community Health. 2007;61.

77. Katon J LK, Simpson T, Williams E, Barnett S, Grossbard J, Schure M, Gray K, Reiber G. Adverse childhood experiences, military. 2015. 
78. Kleykamp M. Unemployment, earnings and enrollment among post 9/ 11 veterans. Social Science Research. 2013;42.

79. Koepsell T, Reiber, G.,Simmons, K. W. Behavioral risk factors and use of preventive services among veterans in Washington State. Preventive Medicine. 2002;35.

80. Koepsell TD, Littman, A. J.,Forsberg, C. W., Obesity, overweight, and their life course trajectories in veterans and non-veterans. Obesity. 2012;20.

81. Kramer BJ, Wang, Mingming, Jouldjian, Stella, Lee, Martin L., Finke, Bruce, Saliba, Debra,. Veterans Health Administration and Indian Health Service: healthcare utilization by Indian Health Service enrollees. Medical Care. 2009;47.

82. Kramer BJ, Jouldjian, Stella, Wang, Mingming, Dang, Jeff, Mitchell, Michael N., Finke, Bruce, Saliba, Debra. Do correlates of dual use by American Indian and Alaska Native veterans operate uniformly across the Veterans Health Administration and the Indian Health Service? Journal of General Internal Medicine. 2011;26.

83. LaCroix AZ, PhD, Rillamas-Sun, Eileen, PhD, MPH,Woods, Nancy F, $\mathrm{PhD}$, RN,Weitlauf, Julie, PhD,Zaslavsky, Oleg, PhD,Shih, Regina, PhD,LaMonte, Michael J, PhD,Bird, Chloe, PhD, MA,Yano, Elizabeth M, PhD, MSPH,LeBoff, Meryl, MD,Washington, Donna, MD, $\mathrm{MPH}$, Reiber, Gayle, PhD, MPH. Aging well among women veterans compared with non-veterans in the Women's Health Initiative. The Gerontologist. 2016;56.

84. Laudet A, Timko, C.,Hill, T. Comparing life experiences in active addiction and recovery between veterans and non-veterans: a national study. Journal of Addictive Diseases. 2014;33.

85. LaVela SL, Prohaska, T. R.,Furner, S.,Weaver, F. M. Preventive healthcare use among males with multiple sclerosis. Public Health. $2012 ; 126$

86. Lehavot K, Hoerster, Katherine D.,Nelson, Karin M.,Jakupcak, Matthew,Simpson, Tracy L. Health indicators for military, veteran, and civilian women. American Journal of Preventive Medicine. 2012;42

87. Lehavot K, Katon, J. G.,Williams, E. C.,Nelson, K. M.,Gardella, C. M.,Reiber, G. E.,Simpson, T. L. Sexual behaviors and sexually transmitted infections in a nationally representative sample of women veterans and nonveterans. Journal of Women's Health. $2014 ; 23$.

88. Lehavot K, O'Hara, Ruth, Washington, Donna L.,Yano, Elizabeth M., Simpson, Tracy L. Posttraumatic stress disorder symptom severity and socioeconomic factors associated with Veterans Health Administration use among women veterans. Women's Health Issues. 2015;25.

89. Lehavot K, PhD, Rillamas-Sun, Eileen, PhD, MPH, Weitlauf, Julie, PhD, Kimerling, Rachel, PhD, Wallace, Robert B, MD. MSc, Sadler Anne G, PhD, RN, Woods, Nancy Fugate, PhD, RN, FAAN, Shipherd, Jillian C, PhD, Mattocks, Kristin, PhD, Cirillo, Dominic J, MD,PhD, Stefanick, Marcia L, PhD, FAHA, Simpson, Tracy L, PhD. Mortality in postmenopausal women by sexual orientation and Veteran status. The Gerontologist. 2016;56.

90. Little RD, Fredland, J Eric. Veteran status, earnings, and race: some long term results. Armed Forces and Society. 1979;5.

91. London AS, Heflin, Colleen M, Wilmoth, Janet M. Work-related disability, veteran status, and poverty: implications for family wellbeing. Journal of Poverty. 2011;15.

92. Long JA, Polsky, Daniel, Asch, David A. Receipt of health services by low-income veterans. Journal of Health Care for the Poor and Underserved. 2003; 14 .

93. Lopreato SC, Poston, Dudley L, Jr. Differences in earnings and earnings ability between Black Veterans and nonveterans in the United States. Social Science Quarterly. 1977;57.

94. MacLean A. Lessons from the Cold War: military service and college education. Sociology of Education. 2005;78.

95. MacLean A, Kleykamp, Meredith. Income inequality and the veteran experience. Annals of the American Academy of Political and Social Science. 2016;663.

96. Marrie RA, Cutter, G.,Tyry, T.,Campagnolo, D.,Vollmer, T. Differences in bladder care for veterans with multiple sclerosis by treatment location. International Journal of MS Care. 2009;11.

97. Martindale M, Poston, Dudley L, Jr. Variations in Veteran/nonveteran earnings patterns among World War II, Korea, and Vietnam War cohorts. Armed Forces and Society. 1979;5.

98. McCarthy JF, Valenstein, Marcia, Dixon, Lisa, Visnic, Stephanie,Blow, Frederic C., Slade, Eric. Initiation of assertive community treatment among veterans with serious mental illness: client and program factors. Psychiatric Services. 2009;60.
99. McCaskill GM, Sawyer, P.,Burgio, K. L.,Kennedy, R.,Williams, C. P.,Clay, O. J.,Brown, C. J.,Allman, R. M. The impact of Veteran status on life-space mobility among Older Black and White men in the Deep South. Ethnicity \& Disease. 2015;25.

100. McCauley HL, Blosnich, John R., Dichter, Melissa E. Adverse childhood experiences and adult health outcomes among veteran and non-veteran women. Journal of Women's Health. 2015;24.

101. McLay RN, Lyketsos, Constantine G. Veterans have less age-related cognitive decline. Military Medicine. 2000;165.

102. Murdoch M, Sayer, Nina A., Spoont, Michele R., Rosenheck, Robert, Noorbaloochi, Siamak, Griffin, Joan M., Arbisi, Paul A., Hagel, Emily M. Long-term outcomes of disability benefits in US veterans with posttraumatic stress disorder. Archives of General Psychiatry. 2011;68.

103. Naifeh JA, North, Terry C., Davis, Joanne L., Reyes, Gilbert, Logan, Constance A., Elhai, Jon D. Clinical profile differences between PTSDdiagnosed military veterans and crime victims. Journal of Trauma \& Dissociation. 2008;9.

104. Nelson KM. The burden of obesity among a national probability sample of Veterans. Journal of General Internal Medicine. 2006;21.

105. Nyamathi A, Sands, Heather, Pattatucci-Aragón, Angela, Berg, Jill, Leake, Barbara, Hahn, Joan Earle, Morisky, Donald. Perception of health status by homeless US Veterans. Family \& Community Health: The Journal of Health Promotion \& Maintenance. 2004;27.

106. O'Donnell JC. Military service and mental health in later life. Military Medicine. 2000;165.

107. Ouimette P, Wolfe, Jessica, Daley, Jennifer, Gima, Kristian. Use of VA Health Care Services by Women Veterans: findings from a national sample. Women \& Health. 2003;38.

108. Padula CB, PhD, Weitlauf, Julie C, PhD, Rosen, Allyson C, PhD, ABPP-CN, Reiber, Gayle, PhD, MPH, Cochrane, Barbara B, PhD, RN, Naughton, Michelle J, PhD, Li, Wenjun, PhD, Rissling, Michelle, PhD, Yaffe, Kristine, MD, Hunt, Julie R, PhD, Stefanick, Marcia L, PhD, Goldstein, Mary K, MD, MS, Espeland, Mark A, PhD. Longitudinal cognitive trajectories of Women Veterans from the Women's Health Initiative Memory Study. The Gerontologist. 2016;56.

109. Petrovich JC, Pollio, D. E.,North, C. S. Characteristics and service use of homeless veterans and nonveterans residing in a low-demand emergency shelter. Psychiatric Services. 2014;65.

110. Phillips BR, Shahoumian, Troy A., Backus, Lisa I. Surveyed enrollees in veterans affairs health care: how they differ from eligible veterans surveyed by BRFSS. Military Medicine. 2015;180.

11. Prokos A, Padavic, Irene. Earn all that you can earn: income differences between women Veterans and non-Veterans. Journal of Political and Military Sociology. 2000;28.

112. Randall M, Kilpatrick, K.E.,Pendergast, J.F.,Jones, K.R.,Vogel, B. Differences in patient characteristics etween Veterans administration and community hospitals. Medical Care. 1987;25.

113. Rosenheck R, Koegel, P. Characteristics of veterans and nonveterans in three samples of homeless men. Hospital \& Community Psychiatry. 1993;44.

114. Rosenheck R, Frisman, Linda, Chung, An-Me. The proportion of veterans among homeless men. American Journal of Public Health. 1994;84.

115. Ryan ET, McGrath, A.,Creech, S.K.,Borsari, B. Predicting utilization of healthcare services in the Veterans Health Administration by returning women Veterans: the role of trauma exposure and symptoms of posttraumatic stress. Psychological Services. 2015; 12 .

116. Saban KL, Bryant, F. B.,Reda, D. J.,Stroupe, K. T.,Hynes, D. M. Measurement invariance of the kidney disease and quality of life instrument (KDQOL-SF) across veterans and non-veterans. Health \& Quality of Life Outcomes. 2010;8.

117. Sayer NA, Orazem, Robert J., Noorbaloochi, Siamak, Gravely, Amy, Frazier, Patricia, Carlson, Kathleen F., Schnurr, Paula P., Oleson, Heather. Iraq and Afghanistan War veterans with reintegration problems: differences by Veterans Affairs healthcare user status. Administration and Policy in Mental Health and Mental Health Services Research. 2015;42.

118. Schultz JR, Bell, Kathryn M., Naugle, Amy E., Polusny, Melissa A. Child sexual abuse and adulthood sexual assault among military Veteran and civilian women. Military Medicine. 2006;171.

119. Shen C, Sambamoorthi, U. Associations between health-related quality of life and financial barriers to care among women veterans and women non-veterans. Women \& Health. 2012;52.

120. Simpson TL, Balsam, Kimberly F.,Cochran, Bryan N., Lehavot, Keren, Gold, Sari D. Veterans administration health care utilization among sexual minority veterans. Psychological Services. 2013;10. 
121. Smith I, Marsh, Kris, Segal, David R. The World War II Veteran advantage? A lifetime cross-sectional study of social status attainment. Armed Forces \& Society. 2012;38.

122. Smith RW, Young, Harl H. Symptom patterns of psychiatrically diagnosed veterans who request treatment and those who do not. Psychological Reports. 1968;22.

123. Sparks PJ, Bollinger, Mary. A demographic profile of obesity in the adult and Veteran US populations in 2008. Population Research and Policy Review. 2011;30.

124. Teachman J. Military service in the Vietnam Era and educational attainment. Sociology of Education. 2005;78.

125. Teachman J. Are veterans healthier? Military service and health at age 40 in the all-volunteer era. Social Science Research. 2011;40.

126. Teachman JD, Call, Vaughn R A. The effect of military service on educational, occupational, and income attainment. Social Science Research. 1996;25.

127. Tessler R, Rosenheck, R.,Gamache, G. Comparison of homeless veterans with other homeless men in a large clinical outreach program. Psychiatric Quarterly. 2002;73.

128. Tessler R, Rosenheck, Robert,Gamache, Gail. Homeless Veterans of the All-Volunteer Force: a social selection perspective. Armed Forces \& Society. 2003;29.

129. Tran TV, Canfield, Julie, Chan, Keith. The association between unemployment status and physical health among veterans and civilians in the United States. Social Work in Health Care. 2016;55.

130. Tsai J, Mares, A. S.,Rosenheck, R. A. Do homeless veterans have the same needs and outcomes as non-veterans? Military Medicine. $2012 ; 177$.

131. Tsai J, Mota, N. P.,Pietrzak, R. H. U.S. Female Veterans who do and do not rely on VA Health Care: needs and barriers to mental health treatment. Psychiatric Services. 2015;66.

132. Vinokur A, Caplan, Robert D., Williams, Cindy C. Effects of recent and past stress on mental health: coping with unemployment among Vietnam veterans and nonveterans. Journal of Applied Social Psychology. $1987 ; 17$

133. Vollmer TL, Hadjimichael, O.,Preiningerova, J.,Ni, W.,Buenconsejo, $\mathbf{J}$. Disability and treatment patterns of multiple sclerosis patients in United States: a comparison of veterans and nonveterans. Journal of Rehabilitation Research \& Development. 2002;39.

134. Washington DL, Yano, E. M.,Simon, B.,Sun, S. To use or not to use. What influences why women veterans choose VA health care. Journal of General Internal Medicine. 2006;21 Suppl 3.

135. Washington DL, MD, MPH, Gray, Kristen, $\mathrm{PhD}$, Hoerster, Katherine D, $\mathrm{PhD}, \mathrm{MPH}$, Katon, Jodie G, PhD, Cochrane, Barbara B, PhD, RN, FAAN,LaMonte, Michael J, PhD, MPH,Weitlauf, Julie C, PhD,Groessl, Erik, PhD,Bastian, Lori, MD, MPH,Vitolins, Mara Z, DrPH, MPH,Tinker, Lesley, $\mathrm{PhD}, \mathrm{RD}$. Trajectories in physical activity and sedentary time among women Veterans in the Women's Health Initiative. The Gerontologist. 2016;56

136. Washington DL, MD, MPH, Bird, Chloe E, PhD, LaMonte, Michael J, PhD, MPH, Goldstein, Karen M, MD, MSPH, Rillamas-Sun, Eileen, PhD, MPH, Stefanick, Marcia L, PhD, Woods, Nancy F, PhD, RN, FAAN, Bastian, Lori A, MD, MPH, Gass, Margery, MD, Weitlauf, Julie C, $\mathbf{P h D}$. Military generation and its relationship to mortality in women Veterans in the Women's Health Initiative. The Gerontologist. 2016;56.

137. West A, Weeks, William B. Physical and mental health and access to care among nonmetropolitan Veterans Health Administration patients younger than 65 years. The Journal of Rural Health. 2006;22.

138. West AN, Weeks, W. B. Health care expenditures for urban and rural veterans in Veterans Health Administration care. Health Services Research. 2009;44.
139. White MD, Mulvey, Philip, Fox, Andrew M, Choate, David. A hero's welcome? Exploring the prevalence and problems of military Veterans in the Arrestee Population. Justice Quarterly. 2012;29.

140. White R, Barber, Catherine, Azrael, Deb, Mukamal, Kenneth J., Miller, Matthew. History of military service and the risk of suicidal ideation: findings from the 2008 National Survey on Drug Use and Health. Suicide and Life-Threatening Behavior. 2011;41.

141. Whiteman SD, Barry, A. E.,Mroczek, D. K.,Macdermid Wadsworth, S. The development and implications of peer emotional support for student service members/veterans and civilian college students. Journal of Counseling Psychology. 2013;60.

142. Widome R, Laska, M. N.,Gulden, A.,Fu, S. S.,Lust, K. Health risk behaviors of Afghanistan and Iraq war veterans attending college. American Journal of Health Promotion. 2011;26.

143. Williams BA, McGuire, J.,Lindsay, R. G.,Baillargeon, J.,Cenzer, I. S.,Lee, S. J.,Kushel, M. Coming home: health status and homelessness risk of older pre-release prisoners. Journal of General Internal Medicine. 2010;25.

144. Wilmoth JM, London, Andrew S., Heflin, Colleen M. Economic wellbeing among older-adult households: variation by veteran and disability status. Journal of Gerontological Social Work. 2015;58.

145. Winkleby MA, Fleshin, D., Physical, addictive, and psychiatric disorders among homeless veterans and nonveterans. Public Health Reports. $1993 ; 108$.

146. Wittrock S, Ono, Sarah, Stewart, Kenda, Reisinger, Heather Schacht, Charlton, Mary. Unclaimed health care benefits: a mixed?method analysis of rural veterans. The Journal of Rural Health. $2015 ; 31$.

147. Wong ES, Wang, Virginia,Liu, Chuan-Fen,Hebert, Paul L.,Maciejewski, Matthew L. Do Veterans Health Administration enrollees generalize to other populations? Medical Care Research and Review. 2016;73.

148. Zemencuk JK, Hayward, R. A.,Skarupski, K. A.,Katz, S. J. Patients' desires and expectations for medical care: a challenge to improving patient satisfaction. American Journal of Medical Quality. 1999;14.

149. Smith DL. The relationship of disability and employment for veterans from the 2010 Medical Expenditure Panel Survey (MEPS). Work. $2015 ; 51$.

150. Bernard DM, Selden TM. Access to care among nonelderly Veterans. Med Care. 2016;54(3):243-52.

151. CDC Mobidity and mortality weekly report rural health series. Accessed March 212018.

152. Felitti VJ, Anda RF, Nordenberg D, Williamson DF, Spitz AM, Edwards V, et al. Relationship of childhood abuse and household dysfunction to many of the leading causes of death in adults. The Adverse Childhood Experiences (ACE) Study. Am J Prev Med. 1998; 14(4):245-58.

153. Affairs DoV. Blueprint for excellence: Veterans Health Administration.

154. Hartley D. Rural health disparities, population health, and rural culture. American Journal of Public Health. 2004;94(10): 1675-8.

155. Wang L, Elder Jr GH, Spence NJ. Status configurations, military service and higher education. Social Forces. 2012;91(2):397-422. 